\title{
Modeling of Open Government Data for Public Sector Organizations Using the Potential Theories and Determinants-A Systematic Review
}

\author{
Muhammad Mahboob Khurshid ${ }^{1,2,3, *(1)}$, Nor Hidayati Zakaria ${ }^{4}$, Ammar Rashid ${ }^{5}$, \\ Mohammad Nazir Ahmad ${ }^{6}$, Muhammad Irfanullah Arfeen ${ }^{7}$ and \\ Hafiz Muhammad Faisal Shehzad 1,3 (D) \\ 1 School of Computing, Faculty of Engineering, Universiti Teknologi Malaysia, Skudai 81310, Johor, Malaysia; \\ muhammad.faisal@uos.edu.pk \\ 2 Department of Examinations, Virtual University of Pakistan, Lahore 54500, Pakistan \\ 3 Department of Computer Science and IT, University of Sargodha, Sargodha 40100, Pakistan \\ 4 Azman Hashim International Business School, Universiti Teknologi Malaysia, \\ Kuala Lumpur 54100, Malaysia; hidayati@utm.my \\ 5 College of Engineering and IT, Ajman University, Ajman 346, UAE; a.rashid@ajman.ac.ae \\ 6 Institute of IR4.0, Universiti Kebangsaan Malaysia, Bangi 43600, Selangor, Malaysia; mnazir@ukm.edu.my \\ 7 Quaid-i-Azam School of Management Sciences, Quaid-i-Azam University, Islamabad 45320, Pakistan; \\ m.arfeen@qau.edu.pk \\ * Correspondence: mahboobkhurshid77@gmail.com
}

Received: 26 May 2020; Accepted: 19 July 2020; Published: 21 July 2020

check for updates

\begin{abstract}
Open government data (OGD) has huge potential to increase transparency, accountability, and participation while improving efficiency in operations, data-driven and evidence-based policymaking, and trust in government institutions. Despite its potential benefits, OGD has not been widely and successfully adopted in public sector organizations, particularly in developing countries. Therefore, the purpose of this study is to explore the theories/frameworks and potential determinants that influence the OGD adoption in public sector organizations. To ascertain the various determinants of OGD adoption in public sector organizations, this study involved a systematic review of already established theories and determinants addressed in the public sector open data domain. The review revealed that the TOE (technology, organization, environment) framework was dominantly employed over theories in the earlier studies to understand organizational adoption to OGD followed by institutional theory. The results, concerning potential determinants, revealed that some of the most frequently addressed determinants are an organization's digitization/digitalization capacity, compliance pressure, financial resources, legislation, policy, regulations, organizational culture, political leadership commitment, top-management support, and data quality. The findings will enrich researchers to empirically investigate the exposed determinants and improve the understanding of decision-makers to leverage OGD adoption by taking relevant measures.
\end{abstract}

Keywords: open (government) data; adoption; diffusion; determinants; systematic review; public sector organizations; TOE framework; institutional theory

\section{Introduction}

"Making public sector information freely available in open formats and ways that enable public access and facilitate exploitation has been termed as open government data (OGD)" [1]. Open government data is a subset of open data and is simply government-related data that is made open to the public [2]. Government data might contain multiple datasets, including budget and 
spending, population, census, geographical, parliament minutes, and scientific data for research, etc. It also includes data that is indirectly 'owned' by public administrations (e.g., through subsidiaries or agencies), such as data related to climate, pollution, public transportation, traffic congestion, childcare, and education and so on [3].

The data are public property and governments are the largest producers and collectors of data $[4,5]$. These data can be used for gaining social commercial value according to different needs and purposes. Several motives urged the need for opening government data. Some of the reasons are transparency, citizens' sense of ownership, recent technological developments, social and commercial value, and participatory governance [6]. Due to the serious harms of corruption on the economy and society and violation of fundamental human rights, democratic societies need to monitor government initiatives and their legitimacy, which would lead to more transparency. The citizens' sense of ownership, i.e., to have access to government data, leads to the opening of more and more data by the governments. Moreover, recent technological developments and peoples' computing skills have made it possible to access, store, manipulate, link, and distribute data and information widely for data-driven innovations. Another reason for sharing more government data with the stakeholders on portals is the provision of opportunities to the public in participating governance processes, decisions, and policymaking [7].

There are several instances, in developed countries like the United States and the United Kingdom, where a large number of datasets are being published online on open data platforms [2]. However, despite the aforementioned motives, the popularity of OGD, and its widespread promotion as an emerging phenomenon and innovation in electronic-government, there is a lack of wide adoption of OGD initiative across different administrative regions [6,8], especially in developing countries [9-11]. This provides motivation and relevance to research in this area. An examination of existing literature suggests that several studies have already been conducted to examine determinants influencing OGD adoption in the context of developed countries and there are some in developing countries context. Before undertaking any further empirical work on this topic, it has been deemed appropriate to undertake a review of existing studies on the organizational adoption of OGD for synthesizing the results reported, thereby identifying their limitations and directions of further work in this important and emerging area. Moreover, to date, no comprehensive review of theories and determinants of organizational adoption of OGD is available. Considering the discussion presented above, this study aims to undertake an analysis and synthesis of relevant research that exists on finding already established theories and issues discussed in such studies related to the organizational adoption of OGD. Hence, based on these facts, the following three research questions are being addressed in this review:

RQ1. What are the already established theories/frameworks used in research addressing organizational adoption of open government data?

RQ2. What are the potential determinants of organizational adoption of open government data?

RQ3. How can a conceptual framework of organizational adoption of open government data based on potential determinants and theories be proposed?

Overall, the contribution of this study is two-fold. First, by synthesizing the literature, this review provides the readers with a comprehensive understanding of current developments of the public sector big open data domain through a comprehensive picture of various theories and adoption determinants of public sector organizations. Second, this review provides up-to-date knowledge for researchers who want to recognize the theoretical lenses and determinants addressed in such studies for conducting comprehensive empirical investigations and to address adoption issues in public sector organizations and devise policy recommendations for policymakers accordingly.

To carry out this review, the remaining part of this submission is structured as follows. The next section briefly describes the employed methodology, followed by findings in Section 3. Section 4 outlines the conclusions section containing theoretical and practical implications, limitations of existing work, and future research directions. 


\section{Methodology}

We have conducted a systematic review based on the guidelines suggested by Kitchenham [12] to answer our scholarly research questions. This section describes the steps of the methodology used to perform the systematic review conducted in this study. A systematic review is a methodical way to identify, evaluate, and interpret the available studies conducted on a topic, research question, or a phenomenon of interest [12]. Kitchenham [12] considers three main phases for a systematic review including Planning the review, conducting the review, and reporting on the review. This research follows the systematic review guidelines suggested by Kitchenham [12] as follows: (1) identify resources; (2) study selection; (3) data extraction; (4) data synthesis; and (5) write-up study as a report. The selection of such methodology is based on the facts that (1) the choice of OGD adoption is inherently problematic affected by several technological, organizational, environmental, business, and perceptional factors, (2) several determinants influence (positive or negative, significant or nonsignificant) an organization's adoption behavior of OGD, and (3) the choice of the determinants by not adopting a "pick and choose" technique, but rather performing a systematic review.

\subsection{Review Protocol}

Review protocol is an essential stage in performing a systematic review and specifies the methods that will be used to undertake a systematic review [12]. The goal of the review protocol is to reduce research bias. The review protocol contains background, research questions, Search strategy, study selection criteria, study selection procedure, quality assessment, the strategy of data extraction, and synthesis of the extracted data [12].

We have identified the research questions that have undertaken the following procedure to carry out the study:

1. Define search term

2. Select digital libraries on which search is to be performed

3. Apply search terms on the selected sources and

4. Select primary studies applying the inclusion and exclusion criteria

To get a complete spectrum of theories, we decided to include all digital libraries in the systematic review (Figure 1).

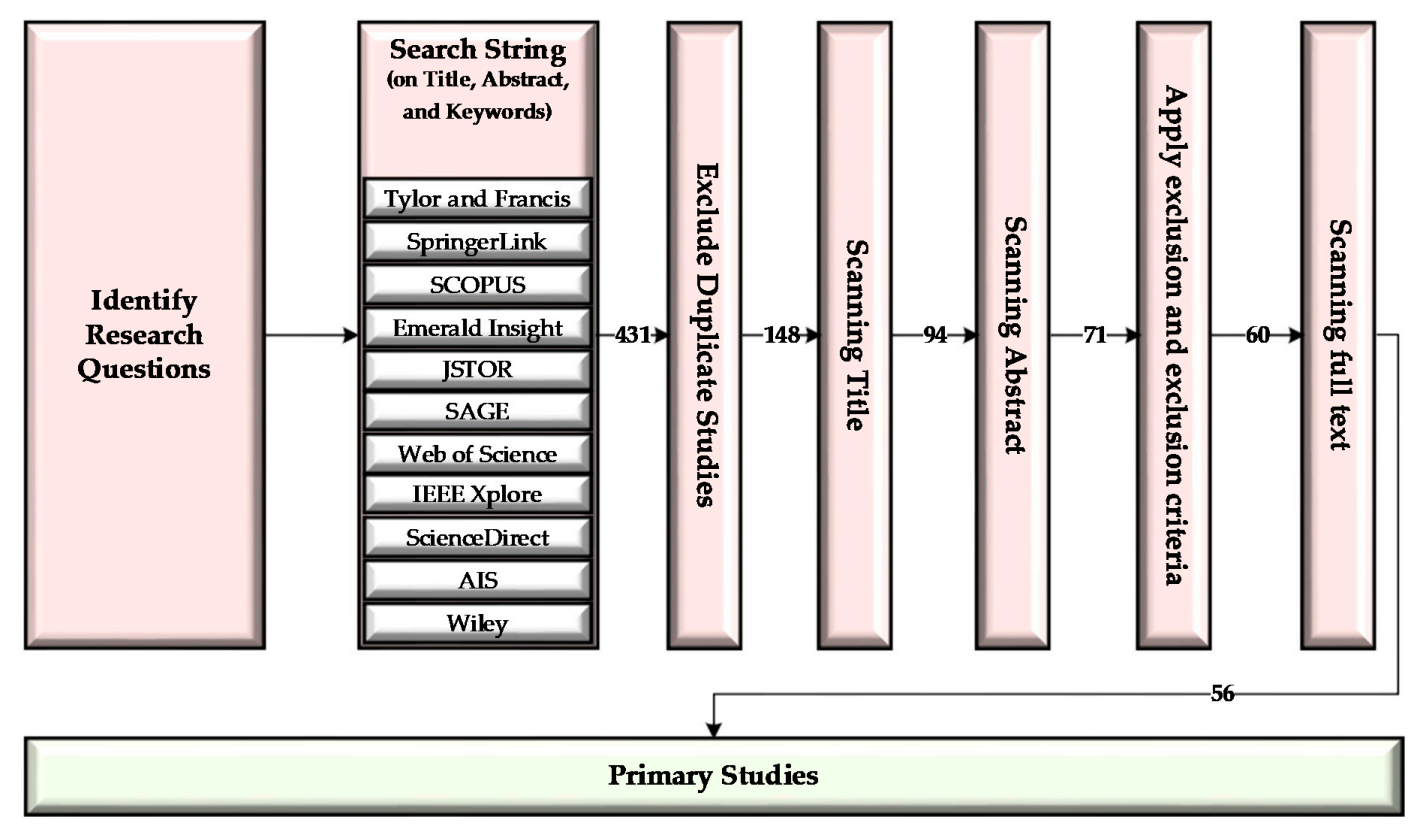

Figure 1. Procedure for identifying primary studies. 


\subsection{Inclusion and Exclusion Criteria}

Inclusion and exclusion criteria are to make sure the selected studies are relevant and related to the current study. This review focused on understanding the public sector open data and the consideration was only given to articles from journals, conferences, and book chapters in the English language. The duration of the selected studies was from 2012 to May 2020. Only the articles having a full text were part of this study. Table 1 shows the complete criteria for inclusion and exclusion of previous studies for this review.

Table 1. Inclusion and Exclusion Criteria.

\begin{tabular}{|c|c|c|}
\hline Criteria & & Description \\
\hline \multirow{6}{*}{ Inclusion Criteria } & $\bigcirc$ & Full-text articles, \\
\hline & 0 & The published period between 2012 and May-2020, \\
\hline & 0 & Written in the English language, \\
\hline & $\bigcirc$ & Related to our research questions, \\
\hline & 0 & In the domain of Open Government, \\
\hline & ○ & Published in the selected digital databases, \\
\hline \multirow{10}{*}{ Excluded Criteria } & 0 & Full text not available, \\
\hline & O & Outside the search time frame, \\
\hline & 0 & The manuscript that was not written in the English language, \\
\hline & 0 & Not related to our research questions, \\
\hline & O & Duplicate studies, \\
\hline & 0 & Research domains like Psychology [13], Medicine, and Mathematics, \\
\hline & 0 & Addressed technical issues like algorithm development, \\
\hline & 0 & Commentaries, \\
\hline & $\bigcirc$ & Articles in press, \\
\hline & 0 & The editorials and opinions and introductory notes on conference proceedings. \\
\hline
\end{tabular}

\subsection{Search Strategy}

We performed the search in metadata fields, i.e., title, abstract, and keyword. Despite that, this search yielded an overwhelming number of publications due to fast-growing developments in OGD. We mainly concentrated on journal articles, book chapters, and the Association for Information Systems (AIS) and IEEE Xplore conferences. The search terms "open data", "open government data", "adoption", "diffusion", "implementation", "success", "performance", "determinants", "factors", "predictors", "antecedents", "organization", "agency", "publishing", "openness" were used and combined by using the Boolean operator "AND". We performed a search in digital libraries, namely:

Web of Science

\section{SCOPUS}

Emerald Insight

JSTOR

ScienceDirect

SAGE

SpringerLink

IEEE Xplore Digital Library

Wiley

Tylor and Francis

AIS Conferences 
For managing and sorting all the studies, Endnote X8.0.2 (manufactured by Clarivate Analytics, Philadelphia, PA, USA), a reference management tool, was used. To keep all the search results and easily remove duplicate studies. Therefore, duplicate studies were removed [12].

\subsection{Study Selection Process}

Thereafter, we went through a screening process by skimming the collected articles to evaluate the best fit with our research questions. The fundamental goal of this research is to review the already established theories/frameworks in the open government domain, and determinants in terms of drivers and inhibitors. Therefore, the selection process of previous studies was carried out based on the research questions mentioned in Section 1. Finally, 56 articles (final set of primary studies) were collected as part of this review.

\subsection{Quality Assessment}

Applying quality assessment is considered critical to assessing the quality of the primary studies [12]. The details of the quality assessment are based on quality instruments. In this review, we developed five quality assessment criteria to assess the quality of each study. These criteria are detailed below:

QA1. Is the topic addressed in the paper related to open government data?

QA2. Is the research methodology described in the paper?

QA3. Is the data collection method described in the paper?

QA4. Are the data analysis steps clearly described in the paper?

QA2. Is it clear in which context the research was carried out?

The four QA criteria presented above were applied to 56 primary studies to enrich our confidence in the credibility of the selected studies.

\section{Findings/Results}

This section is divided into two subheadings, namely general findings and key findings addressing the research questions. It provides a comprehensive view of the literature. Each subheading is expanded into more subheadings to describe the results in more detail.

\subsection{General Findings}

\subsubsection{Publication Source Overview}

As depicted in Table 2, the importance of this review increases because the majority of the studies were published in well-known platforms as well as in leading conferences indexed by Scopus or Web of Science. Primary studies were used to ensure high quality and to provide accurate information on open government data phenomenon. The major distribution of publication sources was journals with forty (40) studies, followed by twelve (12) conference articles, and finally, the rest of the studies were published as book chapters.

Table 2. Publication Type, References and Frequency

\begin{tabular}{cccc}
\hline Sr. No. & Publication Type & References & Frequency \\
\hline 1 & Journal Article & {$[1,2,4,5,7-11,14-44]$} & 40 \\
2 & Conference Paper & {$[6,45-55]$} & 12 \\
3 & Book Section/Chapter & {$[56-59]$} & 4 \\
\hline
\end{tabular}

\subsubsection{Temporal View of Publications}

The publishing of literature on open government data has a short research history. Table 3 shows the distribution of all the studies throughout the period between 2012 and May 2020. Among the 
56 publications, we identified, one study in 2012, two studies in 2013, five studies in 2014, four studies in 2015, ten studies in 2016, seven studies in 2017, eight studies in 2018, and fifteen studies in 2019. However, by the end of May 2020, only four studies are published. This temporal view of publication using theories/frameworks should not be surprising since the concept of open government data is in its early stages of development and few studies have attempted to use already established theories/frameworks.

Table 3. Temporal View of Publications.

\begin{tabular}{cccc}
\hline Sr. No. & Year of Studies & References & Frequency \\
\hline 1 & 2020 & {$[23,40,50,59]$} & 4 \\
2 & 2019 & {$[2,5,9,10,14,25,27,28,37-39,41,52,53,58]$} & 15 \\
3 & 2018 & {$[7,8,11,18,26,32,44,55]$} & 8 \\
4 & 2017 & {$[31,33,35,36,42,46,54]$} & 7 \\
5 & 2016 & {$[1,20,21,24,29,30,43,48,49,51]$} & 10 \\
6 & 2015 & {$[4,17,34,45]$} & 4 \\
7 & 2014 & {$[6,15,19,47,56]$} & 5 \\
8 & 2013 & {$[22,57]$} & 2 \\
9 & 2012 & {$[16]$} & 1 \\
\hline
\end{tabular}

\subsubsection{Research Methods}

There are multiple methodologies involved in the research of open government data including both qualitative and quantitative methods and design science methods. The distributions of the included studies concerning the research methodologies are shown in Table 4.

Table 4. Research Methods.

\begin{tabular}{cccc}
\hline Sr. No. & Research Methods & References & Frequency \\
\hline 1 & Literature Review & {$[23,52,56]$} & 3 \\
2 & Mixed & {$[20,41,43,46,53]$} & 5 \\
3 & Qualitative & {$[4,6-8,10,15-18,24,26-29,31,34-36,40,42,44$,} & 30 \\
4 & Quantitative & $45,47-49,51,54,55,57,59]$ & 15 \\
5 & Action Research & {$[1,2,5,9,11,21,22,25,30,32,33,37-39,58]$} & 1 \\
6 & Conceptual or Theoretical paper & {$[19]$} & 1 \\
7 & Unclear & {$[50]$} & 1 \\
\hline
\end{tabular}

Most of the open government data studies used qualitative methods with 30 studies. The second most commonly used method was quantitative with 15 studies. Other methodologies involved a literature review, mixed (both qualitative and quantitative as well as qualitative and literature review), action research, and conceptual studies with one study each. Further, concerning overall classification, empirical research is dominating over others such as non-empirical and design science (Table 5).

Table 5. Overall Classification of Studies.

\begin{tabular}{cccc}
\hline Sr. No. & Research Methods & References & Frequency \\
\hline 1 & Empirical Research & {$[1,2,4-11,15-18,20-22,24-49,51,53,55-59]$} & 50 \\
2 & Non-Empirical & {$[14,23,52]$} & 3 \\
3 & Design Science & {$[19]$} & 1 \\
4 & Unclear & {$[50,54]$} & 2 \\
\hline
\end{tabular}

\subsubsection{Geographical Distribution of Articles}

This review of theories/frameworks spans over 26 countries (Table 6). The dominant country where most of the studies were conducted in the United States (US) with eight studies, followed by 
seven studies in the Netherlands, five studies each in China and Malaysia, and four studies in Taiwan. Three out of 56 studies were carried out in the United Kingdom (UK), followed by two studies each in Australia, Chile, and Pakistan. Apart from the aforementioned studies, one study was conducted in each of the listed countries, i.e., Brazil, Canada, Europe (EU), India, Indonesia, Saudi Arabia, Singapore, Sweden, Spain, Korea, Turkey, and Ireland. Two studies were conducted considering, simultaneously, multiple countries of the world.

Table 6. Geographical Distribution of Studies.

\begin{tabular}{|c|c|c|c|c|c|c|c|}
\hline Sr. No. & $\begin{array}{l}\text { Country } \\
\text { Name }\end{array}$ & References & Frequency & Sr. No. & $\begin{array}{l}\text { Country } \\
\text { Name }\end{array}$ & References & Frequency \\
\hline 1 & US & {$[6,20,22,31,38,40,55,59]$} & 8 & 14 & Germany & [30] & 1 \\
\hline 2 & Netherlands & {$[14,16,19,24,27,41,57]$} & 7 & 15 & India & [8] & 1 \\
\hline 3 & China & {$[11,25,33,36,48]$} & 5 & 16 & Indonesia & [18] & 1 \\
\hline 4 & Malaysia & {$[10,23,46,50,53]$} & 5 & 17 & Saudi Arabia & [26] & 1 \\
\hline 5 & Taiwan & {$[1,21,34,39]$} & 4 & 18 & Singapore & [5] & 1 \\
\hline 6 & UK & {$[2,15,54]$} & 3 & 19 & Sweden & [35] & 1 \\
\hline 7 & Australia & {$[7,45]$} & 2 & 20 & Korea & [37] & 1 \\
\hline 8 & Chile & {$[4,49]$} & 2 & 21 & Turkey & [52] & 1 \\
\hline 9 & Pakistan & {$[9,58]$} & 2 & 22 & Austria & [42] & 1 \\
\hline 10 & $\begin{array}{l}\text { Multiple } \\
\text { Countries }\end{array}$ & {$[32,44]$} & 2 & 23 & Ireland & {$[51]$} & 1 \\
\hline 11 & Brazil & [56] & 1 & 24 & US and Russia & [43] & 1 \\
\hline 12 & Canada & [29] & 1 & 25 & $\begin{array}{l}\text { Germany and } \\
\text { Spain }\end{array}$ & [47] & 1 \\
\hline 13 & EU & [17] & 1 & 26 & UK and US & {$[28]$} & 1 \\
\hline
\end{tabular}

\subsection{Key Findings Addressing the Research Questions}

\subsubsection{Potential Theories/Models used in the OGD Research}

We have found 34 theories/frameworks during our survey. Among the studies, four theoretical models/frameworks were found dominant over other theories. These were the technology, organization, environment (TOE) framework, institutional theory, diffusion of innovation (DOI) theory, and resource-based theory. Table 7 depicts the complete details of theories/frameworks reported in earlier researches (Supplementary Table S1).

Table 7. List of Theories/Frameworks.

\begin{tabular}{cccc}
\hline Sr. No. & Theories/Frameworks & Frequency & Citations \\
\hline 1 & Technology, Organization, Environment (TOE) & 10 & {$[1,10,23,34,36,38,46,50,52,53]$} \\
2 & Framework & 8 & {$[16,20,21,26,31,33,35,44]$} \\
3 & Institutional Theory & 4 & {$[7,9,20,58]$} \\
4 & Diffusion of Innovation Theory & 3 & {$[6,11,37]$} \\
5 & Resource-Based Theory/View & 1 & {$[47]$} \\
6 & Actor-Network Theory & 1 & {$[30]$} \\
7 & Cognitive Theory & 1 & {$[35]$} \\
8 & The New Public Management Theory & 1 & {$[35]$} \\
9 & The Structuration Theory & 1 & {$[5]$} \\
10 & The System Theory & 1 & {$[4]$} \\
11 & Resource-Dependency Theory & 1 & {$[21]$} \\
12 & Stakeholders Theory / Analyses & 1 & {$[21]$} \\
13 & Technology Acceptance Model (TAM) & 1 & {$[21]$} \\
14 & Unified Theory of Acceptance and Use of & 1 & {$[27]$} \\
15 & Technology (UTAUT) & 1 & {$[3]$} \\
16 & UTAUT2 & 1 & {$[32]$} \\
17 & Strategic Niche Management Theory & 1 & \\
\hline
\end{tabular}


Table 7. Cont.

\begin{tabular}{cccc}
\hline Sr. No. & Theories/Frameworks & Frequency & Citations \\
\hline 18 & Information Orientation Perspective & 1 & {$[6]$} \\
19 & Historical Institutionalism (Path Dependence & 1 & {$[49]$} \\
20 & Theory) & 1 & {$[24]$} \\
21 & Known, Attainable, and Usable Framework & 1 & {$[25]$} \\
22 & Social Network Analysis & 1 & {$[19]$} \\
23 & Business Process Engineering & 1 & {$[28]$} \\
24 & Theory of Organizational Design & 1 & {$[14]$} \\
25 & Karl Popper's View/Theory & 1 & {$[54]$} \\
26 & Nissenbaum's Contextual Integrity Framework & 1 & {$[15]$} \\
27 & Sociological Theory & 1 & {$[2]$} \\
28 & Sebastopol Principles Theory & 1 & {$[51]$} \\
29 & Dynamic Capability Theory & 1 & {$[59]$} \\
30 & Neo-Institutional Theory & 1 & {$[56]$} \\
31 & Organizational Network Theory & 1 & {$[41]$} \\
32 & The Window Theory & 1 & {$[40,55]$} \\
33 & Platform Theory & 1 & {$[43]$} \\
34 & Socio-technical Systems Theory & 1 & {$[42]$} \\
\hline
\end{tabular}

With ten (10) studies, the TOE framework and its extension constitute the most utilized innovation adoption theory/model in the open government data domain. These studies adopted, adapted, and extended TOE across various contexts. The study conducted by Yang and Wu [21] used Institutional Theory with TAM, UTAUT, and UTAUT2 and empirically analyzed the Government agencies' intention and behavior of open data publication in Taiwan. The second most utilized theory was the institutional theory. This theory has also to be utilized by combing some other technology adoption theories such as system theory [16], and the new public management theory and the structuration theory [35]. Another five (5) studies employed this theory as a standalone theory $[20,26,31,33]$. The third most utilized theory was DOI theory whereby it was employed by the four researchers $[7,9,20,58]$. The fourth theory, which was employed mostly, was resource-based theory and it was employed three times [6,11,37]. The remaining twenty-six (30) theories were employed only once whereas some of them were used combinedly. In the domain of tourism, McNaughton and McLeod [60] analyzed the relationship among stakeholders about data exchange using the actor-network theory and highlighted the five key influencers in Jamaica's open data initiatives. The total number of theories employed chronologically is depicted in Figure 2.

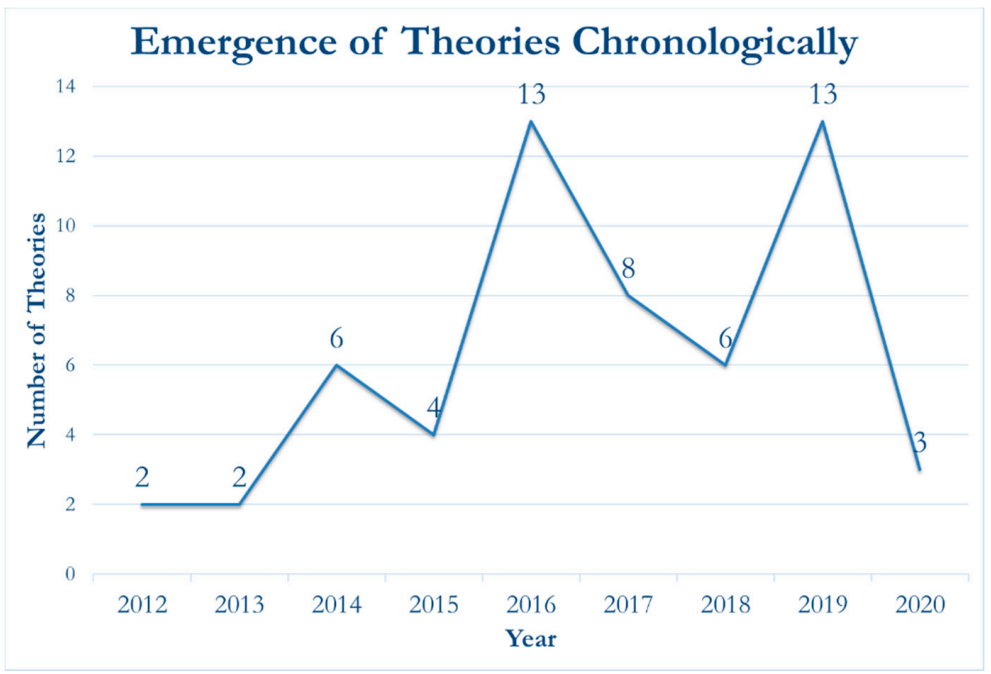

Figure 2. Employed Theories Year-wise. 


\subsubsection{Identified Determinants for the OGD Adoption}

This review revealed that the organization's digitization/digitalizing capacity is the most reported factor of public administrations to publicize the data in open formats. This determinant suggested that technical expertise, information management, and information technology capabilities are outlining predictors of OGD adoption within organizations [21]. Moreover, governments' IT and information management capabilities were also supposed to moderate the relationship of citizens' demand for information and the degree of data openness [6]. The second most prolific factor influencing the government data openness was, according to the review, compliance pressures (such as from public, media, developers) which stimulate the openness of public sector information by the government agencies $[20,21]$. In a similar philosophical lens, external pressures had also been empirically investigated to analyze its effect on the relationship between internal institutional factors and OGD quality [33]. Followed by the two determinants mentioned before, financial resources were another highly contemplated predictor that influence data sharing behavior of government organizations openly $[15,18,23,48]$.

Legislation, policy, regulations, organizational culture, political leadership commitment, top-management support, and data quality were also reported in previous studies as the predictors taken into consideration for organizational adoption of open government data $[23,45,53]$. A complete list of determinants is provided in Table 8.

Table 8. Potential Determinants of OGD Adoption.

\begin{tabular}{|c|c|c|}
\hline Determinants & Frequency & Citations \\
\hline Organization's Digit(i/ali)zation Capacity & 27 & {$[1,4,6,10,11,15-18,21-25,27,31,33,37,38,45,47,48,50-53,57]$} \\
\hline Compliance Pressure & 21 & {$[1,5-7,10,18,20,22,23,26,27,31,33,34,45,48,50,52,53,56,59]$} \\
\hline Financial Resources & 18 & {$[1,6,7,10,15,17,18,21,23-25,37,38,45,47,48,50,52]$} \\
\hline Legislation, Policy, and Regulations & 18 & {$[7,10,16,17,22,23,25,27,30,31,34,38,47,48,50,52,53,56]$} \\
\hline Organizational Culture & 12 & {$[7,10,15,21,23,27,30,34,50,52,53,57]$} \\
\hline Political Leadership Commitment & 10 & {$[7,17,24,26,27,37,45,47,48,57]$} \\
\hline Top-Management Support & 10 & {$[6,17,22,23,29,45,50,52,53,57]$} \\
\hline Data Quality & 10 & {$[2,5,9,10,15,23,25,47,53,57]$} \\
\hline Perceived Effort/Complexity & 9 & {$[15,16,19,21,23,25,34,52,53]$} \\
\hline Perceived Benefits & 8 & {$[1,16,21,23,26,34,53,56]$} \\
\hline Perceived Risks & 6 & {$[6,15,21,22,34,47]$} \\
\hline $\begin{array}{l}\text { Financial Rewards } \\
\text { F }\end{array}$ & 6 & {$[10,18,22,23,50,53]$} \\
\hline Communication and Collaboration with Stakeholders & 6 & {$[4,8,17,18,24,57]$} \\
\hline Security and Privacy & 6 & {$[7,15,19,23,25,57]$} \\
\hline Need for Transparency & 4 & {$[5,7,30,31]$} \\
\hline Vision & 4 & {$[15,24,26,57]$} \\
\hline Relative Advantage & 4 & {$[7,21,50,52]$} \\
\hline Perceived Loss & 4 & {$[15,22,25,34]$} \\
\hline Sensitivity of Function & 4 & {$[5,19,47,57]$} \\
\hline Organization Structure & 4 & {$[7,11,30,48]$} \\
\hline Trust & 4 & {$[18,23,52,53]$} \\
\hline Control of Information by Government & 4 & {$[7,25,27,57]$} \\
\hline Use and Participation Culture & 4 & {$[10,16,24,56]$} \\
\hline Perceived Technical Interoperability & 4 & {$[4,15,17,45]$} \\
\hline Civic Engagement and Public Value Creation & 4 & {$[7,18,48,57]$} \\
\hline Digital Technological Development & 3 & {$[32,38,45]$} \\
\hline Organization's Intention & 3 & {$[21,22,45]$} \\
\hline Business Case/Models & 3 & {$[7,15,57]$} \\
\hline Awareness, Knowledge, and Understanding & 3 & {$[4,11,15]$} \\
\hline Monitoring, Evaluation and Sustainability & 3 & {$[17,29,39]$} \\
\hline Data Format and Metadata & 2 & {$[34,57]$} \\
\hline Gross Domestic Product & 2 & {$[32,38]$} \\
\hline City Population Size & 2 & {$[31,38]$} \\
\hline Organization Size & 2 & {$[5,52]$} \\
\hline Prioritization & 2 & {$[25,27]$} \\
\hline Compatibility & 1 & [50] \\
\hline
\end{tabular}


Table 8. Cont.

\begin{tabular}{ccc}
\hline Determinants & Frequency & Citations \\
\hline Dependence on External Innovators & 1 & {$[5]$} \\
Information Quality & 1 & {$[16]$} \\
Centralized Department/Champion & 1 & {$[27]$} \\
Perceived Barriers & 1 & {$[1]$} \\
Level of Informatization & 1 & {$[34]$} \\
OGD Principles & 1 & {$[50]$} \\
Global Innovation Index & 1 & {$[32]$} \\
Election Turnout & 1 & {$[38]$} \\
Trialability & 1 & {$[57]$} \\
Corruption & 1 & {$[32]$} \\
Citizens Education Level & 1 & {$[38]$} \\
Information System Outsourcing & 1 & {$[34]$} \\
\hline
\end{tabular}

In Table 8, not only the most frequently addressed determinants for the organizational adoption of OGD are listed, but also the factors that are less frequently used in previous studies. The determinants that were used only once in earlier studies include compatibility, dependence on external innovators, information quality, champion, perceived barriers, level of informatization, OGD principles, global innovation index, election turnout, trialability, corruption, citizens education level, and information system outsourcing.

\subsection{Proposed Conceptual Model and Theoretical Model}

To propose a model/framework, several methods were employed in earlier studies. For instance, Hossain and Chan [45] developed the adoption-intention model by conducting an exploratory study. They collected qualitative data by employing in-depth interviews from seven top-echelon staff responsible for the public sector policymaking process and performed coding and thematic analysis techniques to propose the OGD adoption-intention model. A model on measuring the OGD complexity was also developed through the exploratory study on a large number (twenty-seven) of key respondents in the government's information units [34]. In a study conducted by Parung and Hidayanto [61], the fuzzy analytical hierarchy process and technique for order performance by similarity to ideal solution (AHP-TOPSIS) was instigated to address the OGD adoption barriers and proposing the relevant strategies to overcome them. The extent of OGD openness was measured using the production and popularity of datasets on the OGD portal. Other methods to propose the OGD adoption models/frameworks include, for instance, (1) combining systematic literature review (SLR) and employing information systems (IS) theory $[10,23,50]$, and (2) combining SLR, IS theory and an evaluation of the most important predictors by experts' reviews [53].

In this study, a conceptual model has been developed using the guidelines of Jeyaraj, Rottman [62]. The predictors of organizational OGD adoption behavior have been modeled based on the number of times a predictor was addressed to have its influence on OGD adoption behavior in the public sector. Besides, the more frequently addressed variables or constructs in the earlier adoption studies have been selected based on the fact that this method is well-recognized among previous studies on finding the most frequently used influencing factors within the same research area [63]. This method is also helpful in identifying varied significant, non-significant, as well as no relationships. This contributes to a collective decision in developing a hypothesis or interpreting the results [64]. Further, the method of most frequently addressed factors is suitable to highlight the gaps in the existing body of knowledge and to propose patterns for future research found during analysis [65]. This method to develop a conceptual or theoretical model was also employed because several other studies have significantly adopted it, including those of Rana and Dwivedi [63] or Rad and Nilashi [65]. To make the model concise, a predictor is modeled if it is addressed more than twice. Besides, several different factors have been integrated into five different layers, i.e., (1) technology layer, (2) organization layer, (3) environment layer, (4) benefits, barriers, risks, losses (BBRL) layer, and (5) business layer. Figure 3 shows the conceptual/theoretical model of organizational adoption of open government data. 


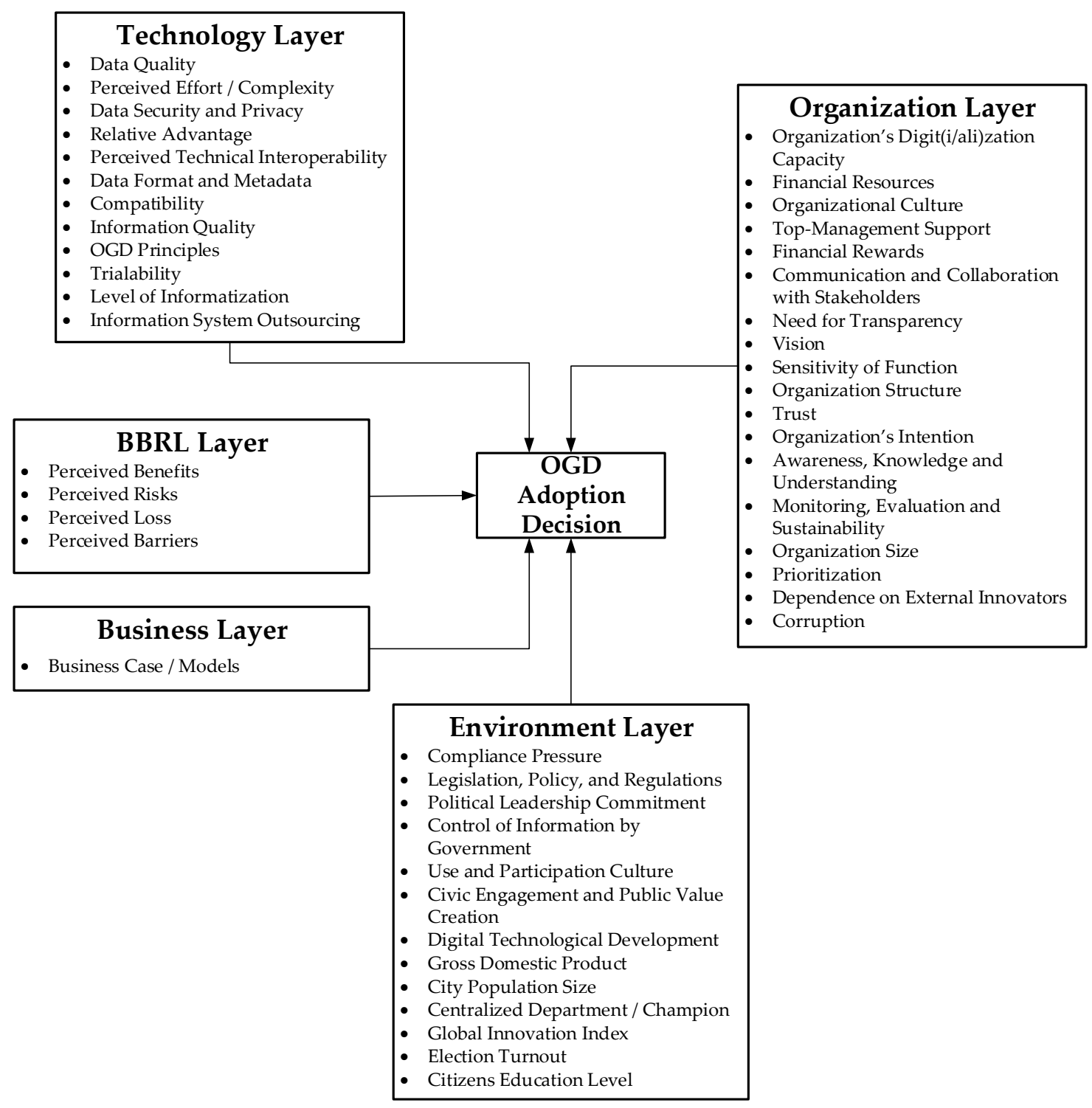

Figure 3. Proposed Model.

\section{Discussion}

The theoretical and practical implications of this study have been presented in the next sections in detail.

\subsection{Theoretical Implications}

The results of this study also have some potentially useful implications theoretically. The development of model (in Section 3.3) is intended to bring out potential determinants (to encourage or discourage) and a clear picture about OGD adoption at organizational level in the public sector. The development of the framework leads significantly to the theory development. Excluding three layers of technology, organization, and environment, the conceptual framework sets up two different layers, namely the business and BBRL layers. The BBRL layer is added because public sector organizations perceive not only technical and operational, but also political, social, and economic types of benefits, barriers, and risks. In this respect, factors of perceived benefits, perceived barriers, and perceived risks are conceptualized as a separate dimension i.e., BBRL layer. Further, although public sector organizations are run on public funds, these organizations are also conducting business activities. Therefore, business layer is also modelled distinctly. The addition of business and BBRL 
layer in the conceptual framework will enhance researcher's understanding on the determinants of OGD adoption in the public sector. An intense collection of these factors provides a precise view of adoption determinants of OGD and also provides contribution to reach to a pooled conclusion [63]. The researchers can obtain useful ideas about determinants of organizational adoption of OGD and different layers under which they are conceptualized for further rigorous testing. The most or less frequently addressed determinants will provide the researchers guidance on making decisions and carefully selecting the appropriate determinants. The proposed framework helps to guide the trending and underrepresented constructs in the open government domain to visualize their impact on OGD adoption decision. The conceptual framework brings forth the development of new constructs, its operationalization, and further testing. The determinants of OGD adoption decision are also helpful in extending existing theories/frameworks with rigorous testing.

\subsection{Practical Implications}

By presenting the conceptual framework helps the practitioners, decision-makers, and governments to successfully integrate and implement OGD in their political process by considering the potential determinants found in earlier studies. The outcome of most frequently addressed determinants of OGD adoption in the public sector organizations raises the relevant points for the governments as well. For instance, governments should ensure OGD implementation by enhancing the technical capacities, improve data sharing culture, developing legal and policy frameworks, and make availability of financial resources in the public sector organizations. It is the will or commitment of the political leadership that could significantly lead the organizations to adopt and implement OGD initiative. Apart from this, the decision-makers being the representatives of organizations can take measures to enhance the OGD use and public participation in policy making. The perceptions about making efforts to produce government data in open formats is also affecting the organizational adoption of OGD for which the decision-makers need to concentrate on and take relevant measures. The organization should realize the transparency and privacy issues, data security and privacy issues, interoperability issues, give importance to user and civic engagement, and public value creation initiatives. Moreover, the adoption of OGD cannot be successful if organizations are not well-aware of and understand the volume, velocity, and value of government data. Moreover, practitioners can make sincere efforts to build the relationship between organizations and external stakeholders by considering the OGD adoption determinants in the public sector.

\section{Research Limitations and Future Research Directions}

There are several actors, such as open data providers, open data intermediaries, and consumers, involved in the open government data ecosystem $[66,67]$. These components build a structural business ecosystem [67] or a closed-loop system [68] because data are provided by the public sector organizations to the public for onward feedback. There are also several boundary conditions within which these actors have to play their roles because these conditions are different for the supply-side and demand-side actors $[40,55]$. However, this study only focuses on data providers, supply-side actors, one-way [68], or data over the wall [69] perspectives in the public sector. Therefore, the first limitation of this study is the that only the determinants of OGD adoption from the supply-side in the public sector are extracted and brought into to develop the model within the sphere of OGD ecosystem. The determinants of intermediaries and consumers are not covered in this study. Thus, integrating the determinants of all the actors will provide a broader picture in the public sector big open data domain. Moreover, since most of the factors are interdependent and influence one another, the relationships have not been built. Secondly, this study has not covered the open data adoption factors of private-sector organizations which may be a significant research progression. Third, since different frameworks for OGD adoption were proposed combining both SLR and interview/coding from the experts, future researchers are encouraged to employ a similar method to regionally contextualize the proposed framework. Fourth, an SLR, a meta-analysis, and accordingly, the weight analysis may 
have a novel contribution and could bring in-depth insights to the OGD adoption studies from the perspective of public sector organizations which should then be rigorously tested in future. Fifth, there are several control variables introduced in earlier research, like institutional status of the chief information officer (CIO), institutionalization of informatization, financial size, financial independence, aging population, population density [37], department type [20], as well as moderating variables like power distance, uncertainty avoidance [11] are introduced. Further research should be carried out, including these control and moderating variables. Finally, although the findings of this study provide a consolidated view of OGD adoption factors, the factors may not be universal in all regional contexts and industry settings. Therefore, researchers are encouraged to appropriately choose the determinants according to the context and industry.

\section{Conclusions}

The main objective of this study is to answer a set of questions mainly concerning the search of all the potential theories and determinants addressed within these studies that influence on OGD adoption in the public sector organization and to propose a model. For this purpose, a systematic review of theories in the public sector and extraction of determinants from academic journals, conferences and book chapters has been made. The review was performed from 2012 to May 2020, during which a total of 56 studies were collected as part of this review process. The main outcome or contribution of this research study is a comprehensive list of theories/frameworks (total 34), potential determinants (total $48)$, and a theoretical/conceptual framework.

Upon reviewing the literature, the determinants are extracted and found impactful on OGD adoption decision in public sector organizations. Moreover, the determinants are consolidated into five layers named technology, organization, environment, business, and BBRL layer. Further, it is found that the TOE framework has been dominantly used in the organizational adoption of OGD, followed by institutional theory, DOI theory, and resource-based theory. With respect to potential determinants, some of the most frequently addressed determinants are organization's digit(i/ali)zation capacity, compliance pressure, financial resources, legislation, policy, and regulations, organizational culture, political leadership commitment, top-management support, and data quality.

Supplementary Materials: The following are available online at http://www.mdpi.com/2227-9709/7/3/24/s1, Table S1: Consolidated Dataset on General Findings.

Funding: This research received no external funding.

Conflicts of Interest: The authors declare no conflict of interest.

\section{References}

1. Wang, H.-J.; Lo, J. Adoption of open government data among government agencies. Gov. Inf. Q. 2016, 33, 80-88. [CrossRef]

2. Wang, V.; Shepherd, D. Exploring the extent of openness of open government data-A critique of open government datasets in the UK. Gov. Inf. Q. 2019, 37, 101405. [CrossRef]

3. Attard, J.; Orlandi, F.; Scerri, S.; Auer, S. A systematic review of open government data initiatives. Gov. Inf. Q. 2015, 32, 399-418. [CrossRef]

4. Gonzalez-Zapata, F.; Heeks, R. The multiple meanings of open government data: Understanding different stakeholders and their perspectives. Gov. Inf. Q. 2015, 32, 441-452. [CrossRef]

5. Zhenbin, Y.; Kankanhalli, A.; Ha, S.; Tayi, G.K. What drives public agencies to participate in open government data initiatives? an innovation resource perspective. Inf. Manag. 2020, 57, 103179. [CrossRef]

6. Agrawal, D.; Kettinger, W.; Zhang, C. The Openness Challenge: Why some cities take it on and others don't. In Proceedings of the Twentieth Americas Conference on Information Systems, Savannah, GA, USA, 7-9 August 2014; pp. 1-7.

7. Chatfield, A.; Reddick, C.G. The role of policy entrepreneurs in open government data policy innovation diffusion: An analysis of Australian Federal and State Governments. Gov. Inf. Q. 2018, 35, 123-134. [CrossRef] 
8. Saxena, S. Proposing a total quality management (TQM) model for open government data (OGD) initiatives: Implications for India. Foresight 2019, 21, 321-331. [CrossRef]

9. Khurshid, M.M.; Zakaria, N.H.; Rashid, A.; Kazmi, R.; Shafique, M.N.; Ahmad, M.N. Analyzing diffusion patterns of big open data as policy innovation in public sector. Comput. Electr. Eng. 2019, 78, 148-161. [CrossRef]

10. Mustapa, M.N.; Hamid, S.; Nasaruddin, F.H.M. Exploring the Issues of Open Government Data Implementation in Malaysian Public Sectors. Int. J. Adv. Sci. Eng. Inf. Technol. 2019, 9, 1466-1473. [CrossRef]

11. Zhao, Y.; Fan, B. Exploring open government data capacity of government agency: Based on the resource-based theory. Gov. Inf. Q. 2018, 35, 1-12. [CrossRef]

12. Kitchenham, B. Guidelines for performing Systematic Literature Reviews in Software Engineering. In EBSE Technical Report; Keele University \& University of Durham: Keele, UK, 2007.

13. Sloman, S.A.; Rabb, N. Your Understanding is My Understanding. Psychol. Sci. 2016, 27, 1451-1460. [CrossRef] [PubMed]

14. Ingrams, A. Administrative Reform and the Quest for Openness: A Popperian Review of Open Government. Adm. Soc. 2019, 52, 319-340. [CrossRef]

15. Martin, C. Barriers to the Open Government Data Agenda: Taking a Multi-Level Perspective. Policy Internet 2014, 6, 217-240. [CrossRef]

16. Janssen, M.; Charalabidis, Y.; Zuiderwijk, A. Benefits, Adoption Barriers and Myths of Open Data and Open Government. Inf. Syst. Manag. 2012, 29, 258-268. [CrossRef]

17. Susha, I.; Zuiderwijk, A.; Charalabidis, Y.; Parycek, P.; Janssen, M. Critical Factors for Open Data Publication and Use: A Comparison of City-level, Regional, and Transnational Cases. JeDEM eJournal eDemocracy Open Gov. 2015, 7, 94-115. [CrossRef]

18. Sayogo, D.S.; Yuli, S.B.C. Critical Success Factors of Open Government and Open Data at Local Government Level in Indonesia. Int. J. Electron. Gov. Res. 2018, 14, 28-43. [CrossRef]

19. Zuiderwijk, A.; Janssen, M.; Choenni, S.; Meijer, R. Design principles for improving the process of publishing open data. Transform. Gov. People Process. Policy 2014, 8, 185-204. [CrossRef]

20. Grimmelikhuijsen, S.G.; Feeney, M.K. Developing and Testing an Integrative Framework for Open Government Adoption in Local Governments. Public Adm. Rev. 2016, 77, 579-590. [CrossRef]

21. Yang, T.-M.; Wu, Y.-J. Examining the socio-technical determinants influencing government agencies' open data publication: A study in Taiwan. Gov. Inf. Q. 2016, 33, 378-392. [CrossRef]

22. Sayogo, D.S.; Pardo, T.A. Exploring the determinants of scientific data sharing: Understanding the motivation to publish research data. Gov. Inf. Q. 2013, 30, S19-S31. [CrossRef]

23. Haini, S.I.; Rahim, N.Z.A.; Zainuddin, N.M.M.; Ibrahim, R. Factors Influencing the Adoption of Open Government Data in The Public Sector: A Systematic Literature Review. Int. J. Adv. Sci. Eng. Inf. Technol. 2020, 10, 611-617. [CrossRef]

24. Donker, F.W.; Van Loenen, B. How to assess the success of the open data ecosystem? Int. J. Digit. Earth 2016, 10, 284-306. [CrossRef]

25. Ma, R.; Lam, P.T. Investigating the barriers faced by stakeholders in open data development: A study on Hong Kong as a "smart city". Cities 2019, 92, 36-46. [CrossRef]

26. Altayar, M.S. Motivations for open data adoption: An institutional theory perspective. Gov. Inf. Q. 2018, 35, 633-643. [CrossRef]

27. Ruijer, E.; Meijer, A. Open Government Data as an Innovation Process: Lessons from a Living Lab Experiment. Public Perform. Manag. Rev. 2019, 43, 613-635. [CrossRef]

28. Ingrams, A. Organizational Design in Open Government: Two Cases from the United Kingdom and the United States. Public Perform. Manag. Rev. 2019, 43, 636-661. [CrossRef]

29. Peter, A.J. Reflecting on the Success of Open Data: How Municipal Government Evaluates their Open Data Programs. Int. J. E-Plan. Res. IJEPR 2016, 5, 1-12.

30. Wirtz, B.W.; Piehler, R.; Thomas, M.-J.; Daiser, P. Resistance of Public Personnel to Open Government: A cognitive theory view of implementation barriers towards open government data. Public Manag. Rev. 2015, 18, 1335-1364. [CrossRef]

31. Ingrams, A. The legal-normative conditions of police transparency: A configurational approach to open data adoption using qualitative comparative analysis. Public Adm. 2017, 95, 527-545. [CrossRef] 
32. Alderete, M.V. The mediating role of ICT in the development of open government. J. Glob. Inf. Technol. Manag. 2018, 21, 1-16. [CrossRef]

33. Fan, B.; Zhao, Y. The moderating effect of external pressure on the relationship between internal organizational factors and the quality of open government data. Gov. Inf. Q. 2017, 34, 396-405. [CrossRef]

34. Yang, T.-M.; Lo, J.; Shiang, J. To open or not to open? Determinants of open government data. J. Inf. Sci. 2015, 41, 596-612. [CrossRef]

35. Kassen, M. Understanding transparency of government from a Nordic perspective: Open government and open data movement as a multidimensional collaborative phenomenon in Sweden. J. Glob. Inf. Technol. Manag. 2017, 20, 236-275. [CrossRef]

36. Zhang, N.; Zhao, X.; Zhang, Z.; Meng, Q.; Tan, H. What factors drive open innovation in China's public sector? A case study of official document exchange via microblogging (ODEM) in Haining. Gov. Inf. Q. 2017, 34, 126-133. [CrossRef]

37. Kim, J.H.; Eom, S.-J. The Managerial Dimension of Open Data Success: Focusing on the Open Data Initiatives in Korean Local Governments. Sustainability 2019, 11, 6758. [CrossRef]

38. Chen, G.; Kang, H.; Luna-Reyes, L. Key Determinants of Online Fiscal Transparency: A TechnologyOrganization-Environment Framework. Public Perform. Manag. Rev. 2018, 42, 606-631. [CrossRef]

39. Jiang, H.; Shao, Q.; Liou, J.J.H.; Shao, T.; Shi, X. Improving the Sustainability of Open Government Data. Sustainability 2019, 11, 2388. [CrossRef]

40. Bonina, C.; Eaton, B. Cultivating open government data platform ecosystems through governance: Lessons from Buenos Aires, Mexico City and Montevideo. Gov. Inf. Q. 2020, 37, 101479. [CrossRef]

41. Matheus, R.; Janssen, M. A Systematic Literature Study to Unravel Transparency Enabled by Open Government Data: The Window Theory. Public Perform. Manag. Rev. 2019, 43, 503-534. [CrossRef]

42. Kornberger, M.; Meyer, R.E.; Brandtner, C.; Höllerer, M.A. When Bureaucracy Meets the Crowd: Studying "Open Government" in the Vienna City Administration. Organ. Stud. 2017, 38, 179-200. [CrossRef]

43. Dawes, S.; Vidiasova, L.; Parkhimovich, O. Planning and designing open government data programs: An ecosystem approach. Gov. Inf. Q. 2016, 33, 15-27. [CrossRef]

44. Kassen, M. Open data and its institutional ecosystems: A comparative cross-jurisdictional analysis of open data platforms. Can. Public Adm. 2018, 61, 109-129. [CrossRef]

45. Hossain, M.; Chan, C. Open data adoption in Australian government agencies: An exploratory study. In Proceedings of the Australasian Conference on Information Systems. arXiv 2016, arXiv:1606.02500.

46. Mustapa, M.N.; Nasaruddin, F.H.M.; Hamid, S. Post-adoption of Open Government Data Initiatives in Public Sectors. In Proceedings of the Pacific Asia Conference on Information Systems, Langkawi Island, Malaysia, 16-20 July 2017; Association for Information Systems: Langkawi, Malaysia, 2017.

47. Hunnius, S.; Krieger, B.; Schuppan, T. Providing, guarding, shielding: Open government data in Spain and Germany. In Proceedings of the European Group for Public Administration Annual Conference, Speyer, German, 10-12 September 2014.

48. Hu, Y.; Bai, X.; Sun, S. Readiness Assessment of Open Government Data Programs. In Proceedings of the 17th International Digital Government Research Conference on Digital Government Research-Dg.o '16, Shanghai, China, 8-10 June 2016; pp. 97-103.

49. Gonzalez-Zapata, F.; Heeks, R. The Influence of the Transparency Agenda on Open Government Data in Chile. In Proceedings of the 2016 Conference for E-Democracy and Open Government (CeDEM), Krems an der Donau, Austria, 18-20 May 2016; Institute of Electrical and Electronics Engineers (IEEE): Piscataway, NJ, USA, 2016; pp. 156-163.

50. Mustapa, M.N.; Nasaruddin, F.H.M.; Hamid, S. Towards a Research Model of Post-adoption of Open Government Data in Malaysia's Public Sector. In Proceedings of the 2020 6th International Conference on Information Management (ICIM), Krems, Austria, 18-20 May 2020; pp. 106-110.

51. Zeleti, F.A.; Ojo, A. Critical Factors for Dynamic Capabilities in Open Government Data Enabled Organizations. In Proceedings of the 17th International Digital Government Research Conference on Digital Government Research-Dg.o '16, Shanghai, China, 8-10 June 2016; 86-96.

52. Çaldağ, M.T.; Gökalp, E.; Alkış, N. Analyzing Determinants of Open Government Based Technologies and Applications Adoption in the Context of Organizations. In Proceedings of the International Conference on e-Learning, e-Business, Enterprise Information Systems, and e-Government (EEE), Las Vegas, NV, USA, 29 July-1 August 2019. 
53. Haini, S.I.; Rahim, N.Z.A.; Zainuddin, N.M.M. Adoption of Open Government Data in Local Government Context. In Proceedings of the 2019 5th International Conference on Computer and Technology Applications-ICCTA 2019, Turkey, Istanbul, 16-17 April 2019; pp. 193-198.

54. Henriksen-Bulmer, J.; Faily, S. Applying Contextual Integrity to Open Data Publishing; Electronic Visualisation and the Arts (EVA 2017): London, UK, 2017; pp. 1-7. [CrossRef]

55. Bonina, C.; Eaton, B.; Henningsson, S. Governing Open Data Platforms to Cultivate Innovation Ecosystems: The Case of the Government of Buenos Aires. In International Conference on Information Systems; Association for Information Systems: San Francisco, CA, USA, 2018.

56. Albano, C.S.; Reinhard, N. Open Government Data: Facilitating and Motivating Factors for Coping with Potential Barriers in the Brazilian Context; Springer Science and Business Media LLC: Berlin, Germany, 2014; Volume 8653, pp. 181-193.

57. Van Veenstra, A.F.; Broek, T.V.D. Opening Moves-Drivers, Enablers and Barriers of Open Data in a Semi-public Organization. In Proceedings of the Intelligent Tutoring Systems, Koblenz, Germany, 16-19 September 2013; Springer Science and Business Media LLC: Berlin, Germany, 2013; Volume 8074, pp. 50-61.

58. Khurshid, M.M.; Zakaria, N.H.; Rashid, A.; Kazmi, R.; Shafique, M.N. Diffusion of Big Open Data Policy Innovation in Government and Public Bodies in Pakistan. In Proceedings of the Biomedical Engineering Systems and Technologies, Prague, Czech Republic, 22-24 February 2019; Springer Science and Business Media LLC: Berlin, Germany, 2019; pp. 326-337.

59. Roa, H.N.; Loza-Aguirre, E.; Flores, P. Drivers and Barriers for Open Government Data Adoption: An Isomorphic Neo-Institutional Perspective; Springer Science and Business Media LLC: Berlin, Germany, 2020; pp. 589-599.

60. McNaughton, M.; McLeod, M.T.; Boxill, I.; Kozak, M.; Kozak, N. An Actor Network Perspective of Tourism Open Data. Tour. Hosp. Manag. 2016, 12, 47-60.

61. Parung, G.A.; Hidayanto, A.N.; Sandhyaduhita, P.I.; Ulo, K.L.M.; Phusavat, K. Barriers and strategies of open government data adoption using fuzzy AHP-TOPSIS. Transform. Gov. People Process. Policy 2018, 12, 210-243. [CrossRef]

62. Jeyaraj, A.; Rottman, J.W.; Lacity, M.C. A Review of the Predictors, Linkages, and Biases in IT Innovation Adoption Research. J. Inf. Technol. 2006, 21, 1-23. [CrossRef]

63. Rana, N.P.; Dwivedi, Y.K.; Williams, M.D. A meta-analysis of existing research on citizen adoption of e-government. Inf. Syst. Front. 2013, 17, 547-563. [CrossRef]

64. Sabherwal, R.; Jeyaraj, A.; Chowa, C. Information System Success: Individual and Organizational Determinants. Manag. Sci. 2006, 52, 1849-1864. [CrossRef]

65. Rad, M.S.; Nilashi, M.; Dahlan, H.M. Information technology adoption: A review of the literature and classification. Univers. Access Inf. Soc. 2017, 17, 361-390. [CrossRef]

66. Ponte, D. Enabling an Open Data Ecosystem. In Proceedings of the European Conference on Information System, Münster, Germany, 26-29 May 2015.

67. Heimstädt, M.; Saunderson, F.; Heath, T. Conceptualizing Open Data ecosystems: A timeline analysis of Open Data development in the UK. In Proceedings of the International Conference for E-Democracy and Open Government (CeDEM2014), Krems, Austria, 21-23 May 2014.

68. Najafabadi, M.M.; Luna-Reyes, L. Open Government Data Ecosystems: A Closed-Loop Perspective. In Proceedings of the 50th Hawaii International Conference on System Sciences, Village, HI, USA, 4-7 January 2017.

69. Sieber, R.E.; Johnson, P.A. Civic open data at a crossroads: Dominant models and current challenges. Gov. Inf. Q. 2015, 32, 308-315. [CrossRef]

(C) 2020 by the authors. Licensee MDPI, Basel, Switzerland. This article is an open access article distributed under the terms and conditions of the Creative Commons Attribution (CC BY) license (http://creativecommons.org/licenses/by/4.0/). 